\title{
Osteonecrosis of the jaws by intravenous bisphosphonates and osteoradionecrosis: A comparative study
}

\author{
Jose V. Bagan ${ }^{1}$, Yolanda Jiménez ${ }^{2}$, Sergio Hernández ${ }^{2}$, Judith Murillo ${ }^{3}$, Jose M. Díaz ${ }^{3}$, Rafael Poveda ${ }^{2}$, \\ Enrique Carbonell ${ }^{2}$, Jose M. Sanchis ${ }^{2}$, Carmen Gavaldá ${ }^{2}$, Crispian Scully ${ }^{4}$
}

\footnotetext{
${ }^{1}$ Professor of Oral Medicine, Head Service of Stomatology, University General Hospital, Valencia University, Spain

${ }^{2}$ Consultant in Dentistry. Valencia University General Hospital, Spain

${ }^{3}$ Consultant in Oral and Maxillofacial Surgery. Valencia University General Hospital, Spain

${ }^{4}$ Professor of Oral Medicine. Eastman Dental Institute, London, UK
}

Correspondence:

Hospital General Universitario

Servicio de Estomatología

Avda. Tres Cruces s $/ n$

46014 - Valencia (Spain)

bagan@uv.es

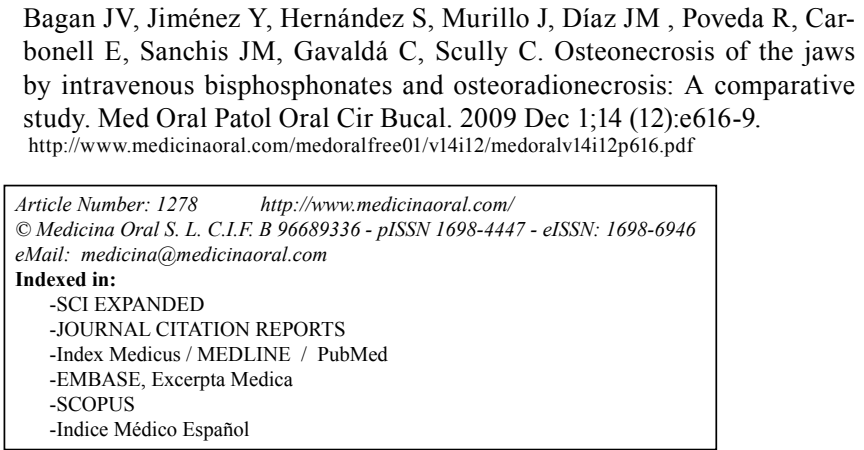

\begin{abstract}
Aims: We analyze the possible clinical differences between bone jaw exposed areas in ONJ (osteonecrosis of the jaws) and ORN (osteoradionecrosis).

Patients and method: Group 1 was composed with 53 ONJ cases and group 2 with 20 ORN cases. In both groups we analyzed, the major size of the exposed bone areas, the number of exposed areas, the location on the jaws and the presence of others associated and severe complications, such as skin fistulas and jaw fractures. We also investigated the possible local aetiology or trigger factor of the lesions.

Results: The major size of the bone exposed areas was $2.29 \pm 2.02$ (mean \pm std.dev) in group 1 and $2.7 \pm 2.9$ (mean \pm std.dev) in group $2(\mathrm{p}>0.05)$. The number of exposed areas was $1.8 \pm 1.34$ (mean \pm std.dev) in group 1 and $1.2 \pm 0.55$ (mean \pm std.dev) in group $2(\mathrm{p}>0.05)$. There were more fractures in the second group $(20 \%)(\mathrm{p}<0.05)$, and skin fistulas $(35 \%)(\mathrm{p}<0.05)$. We found more patients in group 1 in which the dental extraction was the local aetiology of the bone necrosis ( 35 cases, $66.03 \%)$, while in group 2 there were $8(40 \%)(p<0.05)$.

Conclusions: In our study with ONJ there were not differences in the major size of the bone exposed areas, but there were more lesions per patient than in group with ORN. The severity of the complications, such as jaw fractures and skin fistulas were higher in ORN, and in this group it was more frequent the spontaneous lesions than in the ONJ where it is more frequent following dental extractions.
\end{abstract}

Key words: Bisphosphonates, osteonecrosis, osteoradionecrosis, jaws. 


\section{Introduction}

Bisphosphonate treatment for malignant diseases or osteoporosis is common. In the case of malignant diseases, bisphosphonates are usually given intravenously to manage hypercalcemia and bone metastases, such as in the case of multiple myeloma and metastatic breast cancer $(1,2)$. In the case of osteoporosis these drugs are prescribed orally $(3,4)$.

Marx in 2003 (5) reported some of the first described cases of osteonecrosis (osteochemonecrosis) of the jaws (ONJ) As a severe complication from the use of bisphosphonates. Since then there have been many reports (6-11) and Pubmed contains more than 195 articles on this subject.

In ONJ, the jaw bone is exposed with one or several necrotic areas, some cases arising after surgery such as a tooth extraction, but in other cases the origin is unknown (12-14).

ONJ is similar in clinical appearance to osteoradionecrosis (ORN), where the lesions develop after radiotherapy to the head and neck area, typically for the management of malignant tumours. (15-19). ORN mainly occurs when the radiation dose exceeds $65 \mathrm{~Gy}$. The risk to ORN last for many months after radiation treatment. (15).

Although both conditions, ONJ and ORN have been widely described there are no substantial studies published that compare them in terms of the characteristics of the bone lesions, their aetiology and other clinical aspects. The aim of this study was to determine what are the differences if any between ONJ and ORN.

\section{Material and Methods}

We studied two groups. The first (group 1) composed of 53 patients who had developed osteochemonecrosis of the jaws caused by intravenous bisphosphonates for the treatment of malignant diseases (ONJ). We followed the accepted criteria (20) to establish the diagnosis of ONJ. Group 2 was a sample of 20 patients with osteoradionecrosis of the jaws (ORN), the diagnosis being established following the criteria described by Thorn et al. (15).

In both groups we examined the overall size of the exposed bone area, the number of exposed areas, other clinical characteristics such as the location in the jaws and the presence of other severe complications, such as skin fistulas and jaw fractures. We also investigated the possible local aetiology or trigger factors of the lesions. We analyzed the possible association between variables by the $\mathrm{x} 2$ test and the Student $\mathrm{t}$ test to compare the differences between the means in both groups, when the data follow a normal distribution. We considered a difference statistically significant when $\mathrm{p}$ was $<0.05$.
Table 1. Tumor and drugs in group on bisphosphonates.

\begin{tabular}{|l|l|c|c|}
\hline \multirow{5}{*}{ Tumor } & Breast & $\begin{array}{c}\text { Number of } \\
\text { cases }\end{array}$ & \% \\
\hline & Multiple myeloma & 21 & 47.2 \\
\cline { 2 - 4 } & Prostate & 5 & 39.6 \\
\cline { 2 - 4 } & Lung & 1 & 9.4 \\
\cline { 2 - 4 } & Kidney & 1 & 1.9 \\
\hline \multirow{5}{*}{ Bisphosphonate } & $\begin{array}{l}\text { Zoledronic acid } \\
\text { (Zometa } ® \text { ) }\end{array}$ & 51 & 96.2 \\
\cline { 2 - 4 } & $\begin{array}{l}\text { Pamidronate } \\
\text { (Aredia } \AA \text { ) }\end{array}$ & 35 & 66 \\
\hline \multirow{5}{*}{ Other drugs } & Corticosteroids & 20 & 41.7 \\
\cline { 2 - 4 } & Talidomide & 5 & 10.4 \\
\cline { 2 - 4 } & Interpheron & 7 & 14.6 \\
\cline { 2 - 4 } & Chemotherapy & 46 & 95.6 \\
\hline
\end{tabular}

\section{Results}

Most of the patients in Group 1 (ONJ) had either metastatic breast carcinoma or multiple myeloma (Table 1). In 50 cases the number of months on bisphosphonate treatment was known, the mean being $33.4 \pm 17.8$ (std. deviation), (range 10 to 84 months). In most instances (51 out of the 53 cases: $96.2 \%$ ), the patients had been treated with Zoledronic acid (Zometa ${ }^{\circledR}$ ) while there were 18 (34\%) cases on Pamidronate (Aredia $\left.{ }^{\circledR}\right)$.

In Group 2 (ORN), all the patients had developed at least one ORN area, and most patients (18 cases; 90\%) had oral squamous cell carcinoma and the rest had oral lymphomas. The mean radiation dose was $64.85 \mathrm{~Gy} \pm$ 7.9 (std. deviation), (range 48 Gy to $85 \mathrm{~Gy}$ ).

The mean ages in both Groups were not statistically different $(p>0.05)$ but there was a significantly higher number of females in Group $1(\mathrm{p}<0.05)$ (Table 2).

Tobacco and alcohol habits; exposed bone locations, number, and overall size; and other clinical characteristics are shown in table 2 .

\section{Discussion}

Osteonecrosis caused by bisphosphonates (ONJ) or radiotherapy (ONR) manifest primarily by bone exposure. $(5,15)$ Habits such as tobacco and alcohol have been associated with an increased risk of developing areas of ORN but have not been recorded in ONJ. We found in our studio that $22.6 \%$ ONJ patients were smokers, compared with $60 \%$ in the ORN group $(\mathrm{p}<0.05)$.

Thorn et al. (15) found $92 \%$ of patients with ORN were smokers or had been before their radiotherapy. At the time of exposure bone $63(82 \%)$ cases were smokers and $62 \%$ of those had a consumption of 10 or more ciga- 
Table 2. Comparation of the clinical characteristics in ONJ and ORN.

\begin{tabular}{|c|c|c|c|c|c|c|c|c|c|}
\hline & \multicolumn{4}{|c|}{$\begin{array}{l}\text { Group 1: Bisphosphonates } \\
\text { (53 cases) }\end{array}$} & \multicolumn{4}{|c|}{$\begin{array}{c}\text { Group 2: Osteoradionecrosis } \\
\text { (20 cases) }\end{array}$} & \\
\hline Age & \multicolumn{4}{|c|}{63.4} & \multicolumn{4}{|c|}{62.2} & $\mathrm{t}=0.42 \mathrm{p}>0.05$ \\
\hline \multirow{2}{*}{ Gender } & & & \multicolumn{2}{|c|}{ Female } & \multicolumn{2}{|c|}{ Male } & \multicolumn{2}{|c|}{ Female } & \multirow{2}{*}{$\chi^{2}=10.37 \mathrm{p}<0.05$} \\
\hline & $20(3$ & $\%)$ & 33( & $2.3 \%)$ & & & $4(2$ & $\%)$ & \\
\hline Tobacco & \multicolumn{4}{|c|}{$12(22.6 \%)$} & \multicolumn{4}{|c|}{$12(60 \%)$} & $\chi^{2}=9.32 \mathrm{p}<0.05$ \\
\hline Alcohol & \multicolumn{4}{|c|}{$10(19.2 \%)$} & \multicolumn{4}{|c|}{$8(40 \%)$} & $\chi^{2}=3.23 \mathrm{p}=0.06$ \\
\hline \multirow{4}{*}{ Location } & \multicolumn{8}{|c|}{ Mandible } & \\
\hline & \multicolumn{4}{|c|}{$44(83.01 \%)$} & \multicolumn{4}{|c|}{$16(80 \%)$} & $\chi^{2}=3.34 p=0.81$ \\
\hline & \multicolumn{8}{|c|}{ Upper jaw } & \\
\hline & \multicolumn{4}{|c|}{$20(37.7 \%)$} & \multicolumn{4}{|c|}{$4(20 \%)$} & $\chi^{2}=2.59 \mathrm{p}=0.62$ \\
\hline $\begin{array}{l}\text { Number of the bone } \\
\text { exposed areas }\end{array}$ & \multicolumn{4}{|c|}{$1.8 \pm 1.34($ mean \pm std.dev $)$} & \multicolumn{4}{|c|}{$1.2 \pm 0.55($ mean \pm std.dev $)$} & $\mathrm{t}=1.79 \mathrm{p}=0.07$ \\
\hline $\begin{array}{l}\text { Major size of the } \\
\text { bone exposed areas }\end{array}$ & \multicolumn{4}{|c|}{$2.29 \pm 2.02($ mean \pm std.dev $)$} & \multicolumn{4}{|c|}{$2.7 \pm 2.9($ mean \pm std.dev $)$} & $\mathrm{t}=-0.62 \mathrm{p}>0.05$ \\
\hline Jaw fractures & \multicolumn{4}{|c|}{$2(1.8 \%)$} & \multicolumn{4}{|c|}{$4(20 \%)$} & $\chi^{2}=7.14 p<0.05$ \\
\hline Skin fistulas & \multicolumn{4}{|c|}{$1(3.7 \%)$} & \multicolumn{4}{|c|}{$7(35 \%)$} & $\chi^{2}=12.53 p<0.05$ \\
\hline \multirow{2}{*}{ Etiology } & Ext. & $\operatorname{Imp}$ & Prot. & Unk. & Ext. & Imp. & Prot. & Unk. & \\
\hline & 35 & 1 & 5 & 12 & 8 & - & 2 & 10 & $\chi^{2}=12.53 \mathrm{p}<0.05$ \\
\hline
\end{tabular}

Ext.: Extraction; Imp.: Implant; Prot.: Prosthesis; Unk.: Unknown etiology

rettes a day. With regard to alcohol consumption 54\% patients consumed alcohol in varying amounts per day at the time of ORN. Kluth et al. (16) found a relationship between the continuous consumption of alcohol and tobacco and the development of ORN. Marx (12) reported that $83 \%$ of his patients with ORN were smokers.

Several studies (5-9) have demonstrated the higher incidence of ONJ in the mandible, both in intravenous and orally prescribed bisphosphonates, and we could not find differences in between ONJ and ORN in the location $(\mathrm{p}>0.05)$. ORN lesions are known to have a predilection for the molar area of the mandible $(15,21)$ though others found in the symphysis to be the most common location (17).

In the present study we analyzed the overall size of bone lesions and did not find a difference between ONJ and ORN ( $>0.05$ ), the mean size being $2.29 \mathrm{~cm}$ in ONJ and $2.7 \mathrm{~cm}$ in ORN. Thorn et al. (15) measured the radiotransparency in the ortopantomograph in patients with ORN and found that almost half of the cases had between $2-5 \mathrm{~cm}^{2}$ (41\%) followed by areas $0-2 \mathrm{~cm}^{2}$ (34\%), $5-10 \mathrm{~cm}^{2}(18 \%)$ and greater than $10 \mathrm{~cm}^{2}(8 \%)$. In patients with ONJ we found in our previously published study (9) that the average size of the exposed jaw bone areas was $1.96 \mathrm{~cm}$.

We also found in our previous article (9), a mean of 2.3 exposed areas in each patient and a number of authors have reported a greater number of exposed bone areas in
ONJ (5-8). In the present study the number of areas was higher in the ONJ group with an average of $1.8 \pm 1.34$, while in the ORN it was $1.2 \pm 0.55$ but the difference was not statistically significant.

In the present study fractures were found in $1.8 \%$ of our ONJ patients but significantly more frequently in $20 \%$ of ORN cases $(\mathrm{p}<0.05)$. In the case of ORN the study of Thorn (15) reported that the presence of pain in their ORN cases did not clearly correlate with the size of the lesion, but was always present when there were fractures and fistulas (18).

In the present study extractions were the most important aetiologic factor in ONJ but, in ORN, there were many cases $(50 \%)$ in whom the lesions appeared spontaneously (Table 2). This is an important and statistically significant distinction between both processes. $(p<0.05)$. Marx et al. (12) also reported that $37.8 \%$ of their patients with ONJ were associated with dental extractions, $29 \%$ due to periodontal disease and $11 \%$ to periodontal surgery.

The present results differ from the comparative study conducted by Walter et al. (21) but with a lower number of cases in the ONJ group than in ours, where dental treatments were the trigger for ONJ in 13 out of 17 cases, but in the ORN group the importance of the dental treatments as a trigger had less importance, being seen in only 14 of 45 cases. This difference is difficult to explain. 


\section{References}

1. Aapro MS. Management of bisphosphonate treatment in clinical practice. Semin Oncol. 2007;34:S28-32.

2. Saad F, Lipton A. Clinical benefits and considerations of bisphosphonate treatment in metastatic bone disease. Semin Oncol. 2007;34:S17-23.

3. Jeffcoat M, Watts NB. Osteonecrosis of the jaw: balancing the benefits and risks of oral bisphosphonate treatment for osteoporosis. Gen Dent. 2008;56:96-102

4. Khosla S, Burr D, Cauley J, Dempster DW, Ebeling PR, Felsenberg D. Bisphosphonate-associated osteonecrosis of the jaw: report of a task force of the American Society for Bone and Mineral Research. J Bone Miner Res. 2007;22:1479-91.

5. Marx RE.Pamidronate (Aredia) and zoledronate (Zometa) induced avascular necrosis of the jaws: a growing epidemic. J Oral Maxillofac Surg. 2003;61:1115-7.

6. Marx RE, Cillo JE Jr, Ulloa JJ. Oral bisphosphonate-induced osteonecrosis: risk factors, prediction of risk using serum CTX testing, prevention, and treatment. J Oral Maxillofac Surg. 2007;65:2397410.

7. Pazianas M, Miller P, Blumentals WA, Bernal M, Kothawala P. A review of the literature on osteonecrosis of the jaw in patients with osteoporosis treated with oral bisphosphonates: prevalence, risk factors, and clinical characteristics. Clin Ther. 2007;29:1548-58.

8. Bagan JV, Murillo J, Jimenez Y, Poveda R, Milian MA, Sanchis JM, Silvestre FJ, Scully C. Avascular jaw osteonecrosis in association with cancer chemotherapy: series of 10 cases. J Oral Pathol Med. 2005;34:120-3.

9. Bagan JV, Jimenez Y, Murillo J, Hernandez S, Poveda R, Sanchis JM, Diaz JM, Scully C. Jaw osteonecrosis associated with bisphosphonates: multiple exposed areas and its relationship to teeth extractions. Study of 20 cases. Oral Oncol. 2006;42:327-9.

10. Sanna G, Preda L, Bruschini R, Cossu Rocca M, Ferretti S, Adamoli L, Verri E, Franceschelli L, Goldhirsch A, Nolè F. Bisphosphonates and jaw osteonecrosis in patients with advanced breast cancer. Ann Oncol. 2006;17:1512-6.

11. Hansen T, Kunkel M, Weber A, James Kirkpatrick C. Osteonecrosis of the jaws in patients treated with bisphosphonates - histo- morphologic analysis in comparison with infected osteoradionecrosis. J Oral Pathol Med. 2006;35:155-60.

12. Marx RE, Sawatari Y, Fortin M, Broumand V. Bisphosphonateinduced exposed bone (osteonecrosis/osteopetrosis) of the jaws: risk factors, recognition, prevention, and treatment. J Oral Maxillofac Surg. 2005;63:1567-75.

13. Diel IJ, Fogelman I, Al-Nawas B, Hoffmeister B, Migliorati C, Gligorov J, Väänänen K, Pylkkänen L, Pecherstorfer M, Aapro MS. Pathophysiology, risk factors and management of bisphosphonateassociated osteonecrosis of the jaw: Is there a diverse relationship of amino- and non-aminobisphosphonates? Crit Rev Oncol Hematol. 2007;64:198-207.

14. Ruggiero SL, Fantasia J, Carlson E. Bisphosphonate-related osteonecrosis of the jaw: background and guidelines for diagnosis, staging and management. Oral Surg Oral Med Oral Pathol Oral Radiol Endod. 2006;102:433-41.

15. Thorn JJ, Hansen HS, Specht L, Bastholt L. Osteoradionecrosis of the jaws: clinical characteristics and relation to the field of irradiation. J Oral Maxillofac Surg. 2000;58:1088-93; discussion 1093-5.

16. Kluth EV, Jain PR, Stuchell RN, Frich JC Jr.A study of factors contributing to the development of osteoradionecrosis of the jaws.J Prosthet Dent. 1988;59:194-201.

17. Mounsey RA, Brown DH, O'Dwyer TP, Gullane PJ, Koch GH. Role of hyperbaric oxygen therapy in the management of mandibular osteoradionecrosis. Laryngoscope. 1993;103:605-8.

18. Støre G, Boysen M. Mandibular osteoradionecrosis: clinical behaviour and diagnostic aspects. Clin Otolaryngol Allied Sci. 2000;25:378-84.

19. Koga DH, Salvajoli JV, Alves FA. Dental extractions and radiotherapy in head and neck oncology: review of the literature. Oral Dis. 2008;14:40-4.

20. Bagán J, Blade J, Cozar JM, Constela M, García Sanz R, Gómez Veiga F. Recommendations for the prevention, diagnosis, and treatment of osteonecrosis of the jaw (ONJ) in cancer patients treated with bisphosphonates. Med Oral Patol Oral Cir Bucal. 2007;12:E336-40. 21. Walter C, Grötz KA, Kunkel M, Al-Nawas B. Prevalence of bisphosphonate associated osteonecrosis of the jaw within the field of osteonecrosis. Support Care Cancer. 2007;15:197-202. 